\title{
Cholesterol testing among men and women with disability: the role of morbidity
}

This article was published in the following Dove Press journal:

Clinical Epidemiology

I September 2016

Number of times this article has been viewed

\author{
Aisha K Lofters ${ }^{1-3, *}$ \\ Sara JT Guilcher 1,3,4,* \\ Lauren Webster' \\ Richard H Glazier ${ }^{1-3}$ \\ Susan B Jaglal' \\ Ahmed M Bayoumi ${ }^{1,3}$ \\ 'Institute for Clinical Evaluative \\ Sciences, ${ }^{2}$ Department of Family and \\ Community Medicine, St Michael's \\ Hospital, University of Toronto, \\ ${ }^{3}$ Centre for Urban Health Solutions, \\ Li Ka Shing Knowledge Institute, St \\ Michael's Hospital, ${ }^{4}$ Leslie Dan Faculty \\ of Pharmacy, University of Toronto, \\ Toronto, ON, Canada \\ *These authors contributed equally to \\ this work
}

Purpose: Despite more frequent use of health services by people living with disability, the quality of preventive care received may be suboptimal. In this retrospective cohort study, we used administrative data to examine the relationship between cholesterol testing and levels of disability and morbidity among women and men in Ontario, Canada.

Methods: We linked multiple provincial-level databases in this study. In stratified analyses for women and men, we used multivariable logistic regression to examine differences in cholesterol testing, and we tested for an interaction effect between disability and morbidity. In a secondary analysis, we tested for a three-way interaction between sex, disability, and morbidity on the entire cohort.

Results: There was an interaction between morbidity and disability for both women and men. Women and men with no chronic conditions appeared to be least likely to be up-to-date on cholesterol testing, and among this group, those with moderate disability were more likely to be up-to-date on cholesterol testing than those with no disability (adjusted odds ratio [AOR] $=1.51$; $95 \%$ confidence interval [CI] $1.20-1.90$ for women; $\mathrm{AOR}=1.16$; $95 \% \mathrm{CI} 1.00-1.34$ for men). Among women and men who had one chronic condition, having severe disability put them at significant disadvantage versus those with no disability. Only $58.5 \%$ of men with no disability and no chronic conditions were up-to-date on cholesterol testing.

Conclusion: An intermediate level of health care need (reflected in this study as level of disability and level of morbidity) may provide a benefit for cholesterol testing, and conversely, health care needs that are too few or too great may negatively affect testing. Public health and practice-based interventions need to be explored to address these findings.

Keywords: primary care, preventative care, cholesterol testing, disability, morbidity

\section{Introduction}

Disability has been defined as a limitation to performing everyday activities because of a health condition. ${ }^{1,2}$ Despite more frequent use of health services by people living with disability, the quality of care that these individuals receive may be inferior to that of the general population, particularly with regards to preventive care..$^{3-10}$

The relationship between the receipt of preventive care and disability may be complex, with multi-morbidity (ie, the coexistence of at least two chronic conditions) ${ }^{11}$ seeming to play a role. People with disability tend to have higher levels of comorbidity, and morbidity has been associated with such measures of preventive care as unplanned hospital admissions, breast cancer screening, and cervical cancer screening..$^{910,12-14} \mathrm{In}$ previous work, we found an interaction between the levels of disability and morbidity
Correspondence: Aisha Lofters Centre for Research on Inner City Health, Li Ka Shing Knowledge Institute, St Michael's Hospital, 30 Bond Street, Toronto, ON M5B IW8, Canada Email aisha.lofters@utoronto.ca 
for cervical cancer screening, whereby women with a higher level of disability were less likely to be screened than women with a lower level of disability as their level of morbidity increased. ${ }^{9}$ For breast cancer screening, we observed an inverse V-shaped relationship between screening and levels of disability. Women of moderate disability had higher levels of screening than women with no disability (adjusted odds ratio $[\mathrm{AOR}]=1.20 ; 95 \%$ confidence interval $[\mathrm{CI}] 1.09-1.38$ ) and women with severe disability had lower odds of being screened compared to women with moderate disability (AOR $0.72 ; 95 \%$ CI $0.63-0.82$ ). Women with one chronic condition had higher odds of screening than women with no chronic conditions (AOR 1.31; 95\% CI 1.17-1.46). ${ }^{10}$

However, both breast and cervical cancer screening involve procedure-based testing and are limited to women. We know of no studies that have examined the relationship between disability, morbidity, and simpler common secondary prevention tests, such as cholesterol testing performed by venipuncture, for both men and women in Ontario. Cholesterol testing is commonly performed in the primary-care setting and has clear guidelines on testing. ${ }^{15,16}$ Therefore, in this retrospective cohort study, we used provincial-level administrative data to conduct a stratified analysis by sex, examining the relationship between adherence to guidelines for cholesterol testing and levels of disability and morbidity among screen-eligible women and men in Ontario, Canada.

\section{Methods}

\section{Data sources}

We accessed multiple provincial data sources at the Institute for Clinical Evaluative Sciences (ICES), for this study. The 2005 and 2007/2008 Canadian Community Health Surveys (CCHS) were used to identify the cohort. The CCHS is a crosssectional self-report survey administered by Statistics Canada that gathers information on sociodemographics, health status, and health determinants for the Canadian population. Using a unique encoded identifying number that allows individuals to be tracked through multiple databases, we linked respondents from the two aforementioned cycles of CCHS with several administrative health databases. The Ontario Health Insurance Plan (OHIP) Claims contains physicians' fee-for-service claims for Ontario's single-payer health insurance plan, and the Registered Persons Database contains basic demographic and vital statistics information for each Ontario resident. ${ }^{17}$ The Canadian Institute of Health Information Discharge Abstract Database contains fee codes and corresponding diagnostic codes claimed by Ontario's physicians for in-hospital stays or procedures. The Ontario Myocardial Infarction Database
(OMID) identifies all patients with an incident hospital admission for acute myocardial infarction. These datasets were linked using unique encoded identifiers and analyzed at ICES. This study was approved by the institutional review board at Sunnybrook Health Sciences Centre, Toronto, ON, Canada. Patient consent was not required as this was a retrospective study and it would have been infeasible to obtain consent. No direct identifiers were available to the research team.

\section{Study population}

The study population was drawn from respondents to the 2005 CCHS and 2007/2008 CCHS who agreed to have their responses linked with their personal health information at ICES ( $\sim 30,000$ people per CCHS cycle). In order to be included in the study, people needed to be residents of Ontario, alive during the entire observation window, eligible for OHIP during the entire observation window, and had to have answered the Restriction of Activities: Participation and Activity Limitation (RACDPAL) questions on the CCHS. The observation window was defined as the 3 calendar years after completion of the CCHS (ie, January 1, 2006-December 31, 2008, and January 1, 2009-December 31, 2011). Male cohort members needed to be 40-74 years of age and females needed to be 50-74 years of age, during the observation window. These age limits were based on Canadian Cardiovascular Society lipid guidelines. ${ }^{15}$ We excluded individuals who had a diagnosis of myocardial infarction, as per the OMID, at any time on or before the last day of the observation window, as these individuals would not be eligible for cholesterol testing as a preventative measure for the entire 3-year observation window. ${ }^{18}$

\section{Study measures}

We defined cholesterol testing by a binary outcome of whether individuals were or were not up-to-date on cholesterol testing as per guidelines, ${ }^{15} \mathrm{ie}$, having had at least one cholesterol test conducted during the 3-year observation window. The Canadian Cardiovascular Society guidelines recommend cholesterol testing for men who are 40+ years of age and women who are 50+ years of age, and repeating every 3-5 years for those with a Framingham risk score of less than 5\% and annually for those with a score of $5 \%$ or greater. ${ }^{15}$ As we were unable to know participants' Framingham scores with available data, we chose a 3-year time frame. These guidelines are the most commonly used by Canadian physicians. ${ }^{16} \mathrm{We}$ used OHIP fee codes to identify cholesterol testing.

We used the RACDPAL items from the CCHS to define disability. The RACDPAL is based on the response to five questions and classifies respondents by the frequency with which 
they experience activity limitations due to a long-term physical and/or mental health problem that has lasted, or is expected to last 6 months or more. The activity limitations relate to the following questions: 1) Do you have difficulty hearing, seeing, communicating, walking, climbing stairs, bending, learning or doing any similar activities? 2) Does a long-term physical or mental condition or health problem reduce the amount or the kind of activity you can do at home, at work, and at school? 3) Does a long-term physical or mental condition or health problem reduce the amount or the kind of activity you can do in other activities, for example, transportation or leisure? Response options are "often", "sometimes", and "never". If participants answered "never" to all five RACDPAL items, we classified them as having "no disability", and they were used as the reference group. Participants were defined as having "severe disability" if they answered "often" to at least one question. All other participants were classified as having "moderate disability". 9,10 The RACDPAL items were answered by more than $99 \%$ of respondents on both CCHS cycles used.

We defined the level of morbidity on the basis of the self-reported presence of at least one of several chronic conditions noted on the CCHS, namely arthritis, hypertension, COPD, diabetes, heart disease, cancer, stroke, Alzheimer's or other dementias, and mood/anxiety disorder. More than $40 \%$ of Canadian adults have reported having at least one of these conditions. ${ }^{19}$ We categorized participants as having zero, one, or at least two of these chronic conditions, where participants with zero chronic conditions were used as the reference group.

We also included sociodemographic measures from the CCHS, specifically age, ethnicity (country of birth), level of education, and household income. The Rurality Index of Ontario score based on postal codes of residence and the number of physician visits (both primary care and specialist) during the study period was further obtained from administrative databases. ${ }^{20}$

\section{Data analysis}

In stratified analyses for women and men, we conducted descriptive statistics to describe demographics of the study cohort, as well as univariate and bivariate analyses, where all statistical tests were performed at the $5 \%$ level of significance, two-sided, using SAS for Unix, version 9.1.3 (SAS Institute, Cary, NC). We used multivariable logistic regression to examine differences in cholesterol testing. Variables included age as a continuous variable, household income, education, country of birth, rurality, marital status, level of disability, and level of morbidity, and we tested for an interaction effect between disability and morbidity. We excluded participants with missing data from the bivariate and multivariable analyses. All analyses were stratified by sex. In a secondary analysis, we also tested for a three-way interaction between sex, level of morbidity, and level of disability on the entire study cohort, to assess if the effect was different for women versus men.

\section{Results}

Overall, $67.1 \%$ of men $(n=9,313)$ were tested in their 3-year observation window as compared to $77.0 \%$ of women $(n=8,725)$. Table 1 describes the demographic characteristics of the 11,335 women and 13,883 men included in the study cohort. Among both women and men, those with disability had lower income, higher morbidity, and more physician contact during the study period. Women appeared to be more likely to be of lower income and of higher morbidity and to have more physician contact than men, among those both with and without disability. Almost half (48.2\%) of women with disability had two or more chronic conditions as compared to $33.0 \%$ of men with disability.

Table 2 shows the results of the bivariate analyses. Across sociodemographic categories, women and men with moderate disability tended to have the highest risk of up-to-date testing and women and men with no disability tended to have the lowest. A notable exception was among those with one chronic condition and with two or more chronic conditions, where no disability was associated with the highest cholesterol testing and severe disability with the lowest.

When looking at the cross-tabulations of level of morbidity and level of disability (Table 2), for both women and men, the highest risk of up-to-date testing was for those with two or more chronic conditions but no disability ( $83.4 \%$ and $83.3 \%$, respectively), and the lowest risk was for those with no chronic conditions and no disability (69.2\% and $58.5 \%$, respectively). For both sexes, level of morbidity seemed to act as an effect modifier on the relationship between level of disability and cholesterol testing. Although the risk of upto-date testing decreased as level of disability increased for those with at least one chronic condition, this did not hold true for those with no chronic conditions. For those women and men with no chronic conditions, up-to-date testing was highest among those with moderate disability.

In multivariable analyses (Figure 1), the interaction between disability and morbidity remained after adjusting for other variables. For both sexes, a moderate level of disability (versus no disability) was associated with higher adjusted odds of cholesterol testing for those with no chronic conditions. However, this did not hold true for those with some 
Table I Demographic characteristics of I I,335 women and 13,883 men in the study cohort

\begin{tabular}{|c|c|c|c|c|}
\hline & & No disability & Moderate disability & Severe disability \\
\hline Women & & $\mathrm{N}=6,225$ & $\mathrm{~N}=2,580$ & $\mathrm{~N}=2,530$ \\
\hline \multirow[t]{2}{*}{ Age } & Mean \pm SD median (IQR) & $59.7 \pm 6.1$ & $60.4 \pm 6.1$ & $60.3 \pm 6.1$ \\
\hline & & $59(55-65)$ & $60(55-65)$ & $60(55-65)$ \\
\hline \multirow[t]{3}{*}{ Country of birth } & Canada & $4,64 \mid(74.6 \%)$ & 1,985 (76.9\%) & $2,046(80.9 \%)$ \\
\hline & Other & $\mathrm{I}, 455$ (23.4\%) & $541(21.0 \%)$ & $45 \mathrm{I}(17.8 \%)$ \\
\hline & Missing & $129(2.1 \%)$ & $54(2.1 \%)$ & $33(1.3 \%)$ \\
\hline \multirow[t]{4}{*}{ Marital status } & Married/common-law & $4,138(66.5 \%)$ & $1,636(63.4 \%)$ & $\mathrm{I}, 406(55.6 \%)$ \\
\hline & Widowed/single & $\mathrm{I}, 18 \mathrm{I}(19.0 \%)$ & $513(19.9 \%)$ & $568(22.5 \%)$ \\
\hline & Divorced/separated & $903(14.5 \%)$ & $430(16.7 \%)$ & $554(21.9 \%)$ \\
\hline & Missing & $<5(n / a)$ & $<5(n / a)$ & $<5(n / a)$ \\
\hline \multirow[t]{4}{*}{ Education } & $<$ Secondary & $\mathrm{I}, 085(17.4 \%)$ & $529(20.5 \%)$ & $627(24.8 \%)$ \\
\hline & Secondary or some post-secondary & I,769 (28.4\%) & $643(24.9 \%)$ & $616(24.3 \%)$ \\
\hline & Post-secondary & $3,350(53.8 \%)$ & I,399 (54.2\%) & I,277 (50.5\%) \\
\hline & Missing & $21(0.3 \%)$ & $9(0.3 \%)$ & $10(0.4 \%)$ \\
\hline \multirow[t]{5}{*}{ Household income } & $<\$ 30,000$ & $1,112(17.9 \%)$ & $607(23.5 \%)$ & $907(35.8 \%)$ \\
\hline & $\$ 30,000$ to $<\$ 59,999$ & I,935 (31.1\%) & $806(31.2 \%)$ & $766(30.3 \%)$ \\
\hline & $\$ 60,000$ to $<\$ 99,999$ & $1,436(23.1 \%)$ & $573(22.2 \%)$ & $404(16.0 \%)$ \\
\hline & $\$ 100,000+$ & I,I06 (I7.8\%) & $360(14.0 \%)$ & 231 (9.1\%) \\
\hline & Missing & $636(10.2 \%)$ & $234(9.1 \%)$ & 222 (8.8\%) \\
\hline Rurality Index of Ontario & 0-9 (large urban) & $3,006(48.3 \%)$ & $1,228(47.6 \%)$ & I,I7I (46.3\%) \\
\hline \multirow[t]{3}{*}{ score } & 10-44 (small urban) & $2,261(36.3 \%)$ & $966(37.4 \%)$ & $988(39.1 \%)$ \\
\hline & $45+($ rural $)$ & $867(13.9 \%)$ & $343(13.3 \%)$ & 345 (13.6\%) \\
\hline & Missing & 91 (1.5\%) & $43(1.7 \%)$ & $26(1.0 \%)$ \\
\hline \multirow[t]{4}{*}{ Morbidity } & No chronic conditions & $2,9 \mid 3(46.8 \%)$ & $563(21.8 \%)$ & $345(13.6 \%)$ \\
\hline & 1 & $1,118(18.0 \%)$ & 977 (37.9\%) & $763(30.2 \%)$ \\
\hline & $2+$ & $2,194(35.2 \%)$ & $\mathrm{I}, 040(40.3 \%)$ & $\mathrm{I}, 422(56.2 \%)$ \\
\hline & Missing & $<5(n / a)$ & $<5(n / a)$ & $<5(n / a)$ \\
\hline Number of physician & Mean \pm SD & $16.4 \pm 15.4$ & $21.8 \pm 18.2$ & $27.8 \pm 22.5$ \\
\hline visits during study period & Median (IQR) & $13(7-22)$ & $18(10-28)$ & $23(13-37)$ \\
\hline Men & & $\mathrm{N}=8,528$ & $\mathrm{~N}=2,832$ & $\mathrm{~N}=2,523$ \\
\hline \multirow[t]{2}{*}{ Age } & Mean \pm SD & $53.5 \pm 9.1$ & $55.5 \pm 9.0$ & $56.0 \pm 8.7$ \\
\hline & Median (IQR) & $53(45-6 I)$ & $56(48-63)$ & $56(49-63)$ \\
\hline \multirow[t]{3}{*}{ Country of birth } & Canada & $6,370(74.7 \%)$ & $2,269(80.1 \%)$ & $2,076(82.3 \%)$ \\
\hline & Other & $1,940(22.7 \%)$ & $519(18.3 \%)$ & $406(16.1 \%)$ \\
\hline & Missing & $218(2.6 \%)$ & $44(1.6 \%)$ & $4 \mathrm{I}(1.6 \%)$ \\
\hline \multirow[t]{4}{*}{ Marital status } & Married/common-law & $6,096(71.5 \%)$ & $1,930(68.1 \%)$ & $1,609(63.8 \%)$ \\
\hline & Widowed/single & $1,316(15.4 \%)$ & $502(17.7 \%)$ & 434 (I7.2\%) \\
\hline & Divorced/separated & $1,114(13.1 \%)$ & $398(14.1 \%)$ & $475(18.8 \%)$ \\
\hline & Missing & $<5(n / a)$ & $<5(n / a)$ & $<5(n / a)$ \\
\hline \multirow[t]{4}{*}{ Education } & $<$ Secondary & $\mathrm{I}, 24 \mathrm{I}(\mathrm{I} 4.6 \%)$ & $522(18.4 \%)$ & $590(23.4 \%)$ \\
\hline & Secondary or some post-secondary & $\mathrm{I}, 93 \mathrm{I}(22.6 \%)$ & $633(22.4 \%)$ & $536(21.2 \%)$ \\
\hline & Post-secondary & $5,319(62.4 \%)$ & $\mathrm{I}, 667$ (58.9\%) & $1,379(54.7 \%)$ \\
\hline & Missing & $37(0.4 \%)$ & $10(0.4 \%)$ & $18(0.7 \%)$ \\
\hline \multirow[t]{5}{*}{ Household income } & $<\$ 30,000$ & $866(10.2 \%)$ & $429(15.1 \%)$ & $678(26.9 \%)$ \\
\hline & $\$ 30,000$ to $<\$ 59,999$ & $2,133(25.0 \%)$ & $797(28.1 \%)$ & $70 \mathrm{I}(27.8 \%)$ \\
\hline & $\$ 60,000$ to $<\$ 99,999$ & $2,554(29.9 \%)$ & 799 (28.2\%) & $589(23.3 \%)$ \\
\hline & $\$ 100,000+$ & $2,518(29.5 \%)$ & $665(23.5 \%)$ & $405(16.1 \%)$ \\
\hline & Missing & 457 (5.4\%) & $142(5.0 \%)$ & $150(5.9 \%)$ \\
\hline Rurality Index of Ontario & 0-9 (large urban) & $4,507(52.8 \%)$ & $1,405(49.6 \%)$ & $1,073(42.5 \%)$ \\
\hline \multirow[t]{3}{*}{ score } & 10-44 (small urban) & $2,929(34.3 \%)$ & $1,035(36.5 \%)$ & $990(39.2 \%)$ \\
\hline & $45+($ rural) & 989 (II.6\%) & $35 \mathrm{I}(12.4 \%)$ & $426(16.9 \%)$ \\
\hline & Missing & $103(1.2 \%)$ & 41 (I.4\%) & $34(1.3 \%)$ \\
\hline \multirow[t]{4}{*}{ Morbidity } & No chronic conditions & $5,311(62.3 \%)$ & $1,099(38.8 \%)$ & $648(25.7 \%)$ \\
\hline & I & $2,265(26.6 \%)$ & $985(34.8 \%)$ & $855(33.9 \%)$ \\
\hline & $2+$ & $952(11.2 \%)$ & $748(26.4 \%)$ & $1,020(40.4 \%)$ \\
\hline & Missing & $<5(n / a)$ & $<5(\mathrm{n} / \mathrm{a})$ & $<5(\mathrm{n} / \mathrm{a})$ \\
\hline Number of physician & Mean \pm SD & $12.6 \pm 13.8$ & $17.6 \pm 19.2$ & $23.0 \pm 23.0$ \\
\hline visits during study period & Median (IQR) & $9(4-17)$ & $13(6-23)$ & $17(8-3 \mid)$ \\
\hline
\end{tabular}

Notes: All percentages reported are column percentages.

Abbreviations: SD, standard deviation; n/a, not applicable; IQR, interquartile range. 
Table 2 Number and percentage of participants up-to-date on cholesterol testing by level of disability and sociodemographic characteristics, stratified by sex

\begin{tabular}{|c|c|c|c|c|}
\hline & & No disability & Moderate disability & Severe disability \\
\hline \multicolumn{5}{|l|}{ Women } \\
\hline \multirow[t]{2}{*}{ Country of birth } & Canada & $3,410(73.5 \%)$ & I,56I (78.6\%) & I,538 (75.2\%) \\
\hline & Other & $\mathrm{I}, 202(82.6 \%)$ & $462(85.4 \%)$ & $383(84.9 \%)$ \\
\hline \multirow[t]{3}{*}{ Marital status } & Married/common-law & $3,185(77.0 \%)$ & $\mathrm{I}, 30 \mathrm{I}(79.5 \%)$ & $\mathrm{I}, 09 \mathrm{I}(77.6 \%)$ \\
\hline & Widowed/single & $878(74.3 \%)$ & $426(83.0 \%)$ & 427 (75.2\%) \\
\hline & Divorced/separated & 647 (71.7\%) & $333(77.4 \%)$ & $432(78.0 \%)$ \\
\hline \multirow[t]{3}{*}{ Education } & $<$ Secondary & $820(75.6 \%)$ & $405(76.6 \%)$ & $470(75.0 \%)$ \\
\hline & Secondary or some post-secondary & I,345 (76.0\%) & $525(81.6 \%)$ & 475 (77.1\%) \\
\hline & Post-secondary & $2,533(75.6 \%)$ & I, $123(80.3 \%)$ & 999 (78.2\%) \\
\hline \multirow[t]{4}{*}{ Household income } & $<\$ 30,000$ & $822(73.9 \%)$ & $465(76.6 \%)$ & $684(75.4 \%)$ \\
\hline & $\$ 30,000$ to $<\$ 59,999$ & I,429 (73.9\%) & $658(81.6 \%)$ & 595 (77.7\%) \\
\hline & $\$ 60,000$ to $<\$ 99,999$ & I, I06 (77.0\%) & $475(82.9 \%)$ & $313(77.5 \%)$ \\
\hline & $\$ 100,000+$ & $868(78.5 \%)$ & $289(80.3 \%)$ & 179 (77.5\%) \\
\hline \multirow[t]{3}{*}{ Rurality Index of Ontario score } & 0-9 (large urban) & 2,447 (8I.4\%) & $\mathrm{I}, 044(85.0 \%)$ & 957 (81.7\%) \\
\hline & I0-44 (small urban) & $\mathrm{I}, 724(76.2 \%)$ & $784(81.2 \%)$ & 775 (78.4\%) \\
\hline & $45+$ (rural) & $489(56.4 \%)$ & $209(60.9 \%)$ & $203(58.8 \%)$ \\
\hline \multirow[t]{3}{*}{ Morbidity } & No chronic conditions & $2,016(69.2 \%)$ & $432(76.7 \%)$ & 254 (73.6\%) \\
\hline & 1 & $\mathrm{I}, 765$ (80.4\%) & 77 ( $78.9 \%)$ & $572(75.0 \%)$ \\
\hline & $2+$ & $932(83.4 \%)$ & $858(82.5 \%)$ & I,I 25 (79.1\%) \\
\hline \multicolumn{5}{|l|}{ Men } \\
\hline \multirow[t]{2}{*}{ Country of birth } & Canada & $3,975(62.4 \%)$ & I,562 (68.8\%) & I,394 (67.1\%) \\
\hline & Other & I,454 (74.9\%) & $402(77.5 \%)$ & 306 (75.4\%) \\
\hline \multirow[t]{3}{*}{ Marital status } & Married/common-law & $4,214(69.1 \%)$ & $\mathrm{I}, 428(74.0 \%)$ & I,I 159 (72.0\%) \\
\hline & Widowed/single & 725 (55.1\%) & $317(63.1 \%)$ & 257 (59.2\%) \\
\hline & Divorced/separated & $643(57.7 \%)$ & $254(63.8 \%)$ & $310(65.3 \%)$ \\
\hline \multirow[t]{3}{*}{ Education } & $<$ Secondary & $782(63.0 \%)$ & $355(68.0 \%)$ & $393(66.6 \%)$ \\
\hline & Secondary or some post-secondary & I,253 (64.9\%) & $433(68.4 \%)$ & $363(67.7 \%)$ \\
\hline & Post-secondary & $3,522(66.2 \%)$ & $\mathrm{I}, 204(72.2 \%)$ & $964(69.9 \%)$ \\
\hline \multirow[t]{4}{*}{ Household income } & $<\$ 30,000$ & $526(60.7 \%)$ & $292(68.1 \%)$ & $440(64.9 \%)$ \\
\hline & $\$ 30,000$ to $<\$ 59,999$ & I,377 (64.6\%) & $539(67.6 \%)$ & $492(70.2 \%)$ \\
\hline & $\$ 60,000$ to $<\$ 99,999$ & I,668 (65.3\%) & $555(69.5 \%)$ & 406 (68.9\%) \\
\hline & $\$ 100,000+$ & $\mathrm{I}, 72 \mathrm{I}(68.3 \%)$ & $505(75.9 \%)$ & 289 (7I.4\%) \\
\hline \multirow[t]{3}{*}{ Rurality Index of Ontario score } & 0-9 (large urban) & $3,150(69.9 \%)$ & I,062 (75.6\%) & 771 (71.9\%) \\
\hline & I0-44 (small urban) & I,894 (64.7\%) & $728(70.3 \%)$ & 707 (7I.4\%) \\
\hline & $45+($ rural) & 492 (49.7\%) & $184(52.4 \%)$ & 234 (54.9\%) \\
\hline \multirow[t]{3}{*}{ Morbidity } & No chronic conditions & 3,107 (58.5\%) & $680(61.9 \%)$ & $398(61.4 \%)$ \\
\hline & I & I,683 (74.3\%) & $713(72.4 \%)$ & $554(64.8 \%)$ \\
\hline & $2+$ & $793(83.3 \%)$ & $606(81.0 \%)$ & 779 (76.4\%) \\
\hline
\end{tabular}

Notes: All percentages reported are column percentages.

Abbreviations: SD, standard deviation; $n / a$, not applicable; IQR, interquartile range.

level of morbidity. For both sexes, severe disability (versus no disability) was associated with lower adjusted odds of cholesterol testing for those with one chronic condition.

In our secondary analysis, the three-way interaction between sex, level of disability, and level of morbidity was not significant $(P=0.97)$, suggesting no difference in effect between women and men.

\section{Interpretation}

We have found that, in Ontario, morbidity acts as an effect modifier on the relationship between level of disability and adherence to guidelines for cholesterol testing. The number of chronic conditions appeared to differentiate those who were up-to-date most strongly, with women and men with no chronic conditions being least likely to be up-to-date on cholesterol testing. Among those with no chronic conditions, women and men living with a moderate level of disability were more likely to be up-to-date on cholesterol testing than those with no disability. Among women and men who had one chronic condition, also having a severe disability put them at a significant disadvantage compared to those with no disability. Additionally, we found that, across sexes and levels of disability and morbidity, men with no disability and no chronic conditions had the lowest risk of appropriate cholesterol testing, where only $58.5 \%$ of these men were upto-date on testing and that Ontarians living with disability 
A

Age

\section{Education}

Less than secondary vs post secondary

Secondary vs post-secondary

Household income

$<\$ 30,000$ vs $\$ 100,000+$

$\$ 30,000-59,999$ vs $\$ 100,000+$

$\$ 60,000-99,999$ vs $\$ 100,000+$

Rurality index

Small urban vs large urban

Rural vs large urban

Country of birth

Other vs Canada

Marital status

Widowed/single vs married/common-law

Separated/divorced vs married/cormmon-law Disability

Moderate vs no disability

Severe vs no disability

Chronic conditions

1 vs 0 conditions

$2+$ vs 0 conditions

Disability ${ }^{*}$ chronic conditions

Moderate vs no disability ( 0 conditions) Severe vs no disability (0 conditions)

Moderate vs no disability ( 1 condition)

Severe vs no disability ( 1 condition)

Moderate vs no disability ( $2+$ conditions)

Severe vs no disability ( $2+$ conditions)

B

\section{Age}

Education

Less than secondary vs post secondary

Secondary vs post-secondary

Household income

$<\$ 30,000$ vs $\$ 100,000+$

$\$ 30,000-59,999$ vs $\$ 100,000+$

$\$ 60,000-99,999$ vs $\$ 100,000+$

Rurality index

Small urban vs large urban

Rural vs large urban

Country of birth

Other vs Canada

Marital status

Widowed/single vs married/common-law

Separated/divorced vs married/cormmon-law

Disability

Moderate vs no disability

Severe vs no disability

Chronic conditions

1 vs 0 conditions

2+ vs 0 conditions

Disability*chronic conditions

Moderate vs no disability (0 conditions)

Severe vs no disability ( 0 conditions)

Moderate vs no disability ( 1 condition)

Severe vs no disability ( 1 condition)

Moderate vs no disability ( $2+$ conditions)

Severe vs no disability ( $2+$ conditions)

\section{OR (Cl)}

$1.04(1.03-1.05)$

$0.84(0.73-0.96)$

$1.00(0.89-1.12)$

$0.69(0.57-0.83)$

$0.77(0.65-0.90)$

$0.97(0.83-1.14)$

$0.83(0.74-0.93)$

$0.32(0.28-0.37)$

$1.35(1.18-1.53)$

$0.89(0.78-1.02)$

$0.88(0.76-1.01)$

$1.51(1.20-1.90)$

1.24 (0.95-1.63)

1.83 (1.58-2.12)

2.33 (1.91-2.84)

$1.51(1.20-1.90)$

1.24 (0.95-1.63)

$0.99(0.81-1.22)$

$0.77(0.62-0.95)$

$1.01(0.78-1.30)$

$0.81(0.65-1.01)$

$$
0.5
$$

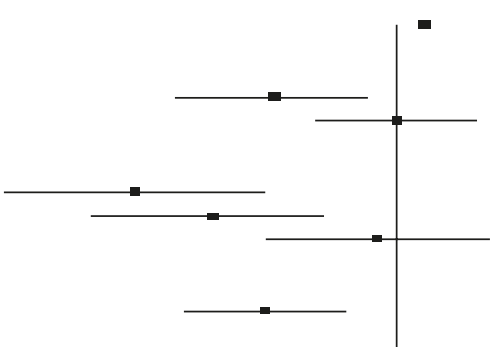

OR (CI)

1.05 (1.05-1.06)

$0.83(0.74-0.93)$

$1.01(0.92-1.12)$

$0.63(0.54-0.73)$

$0.73(0.65-0.83)$

$0.86(0.77-0.95)$

$0.79(0.72-0.86)$

$0.37(0.32-0.41)$

$1.34(1.21-1.49)$

$0.69(0.62-0.78)$

$0.72(0.64-0.81)$

$1.16(1.00-1.34)$

$1.16(0.97-1.39)$

$1.86(1.65-2.10)$

$2.90(2.38-3.54)$

$1.16(1.00-1.34)$

$1.16(0.97-1.39)$

$0.87(0.73-1.05)$

$0.74(0.61-0.89)$

$0.88(0.67-1.15)$

0.83 (0.65-1.07)

0.5
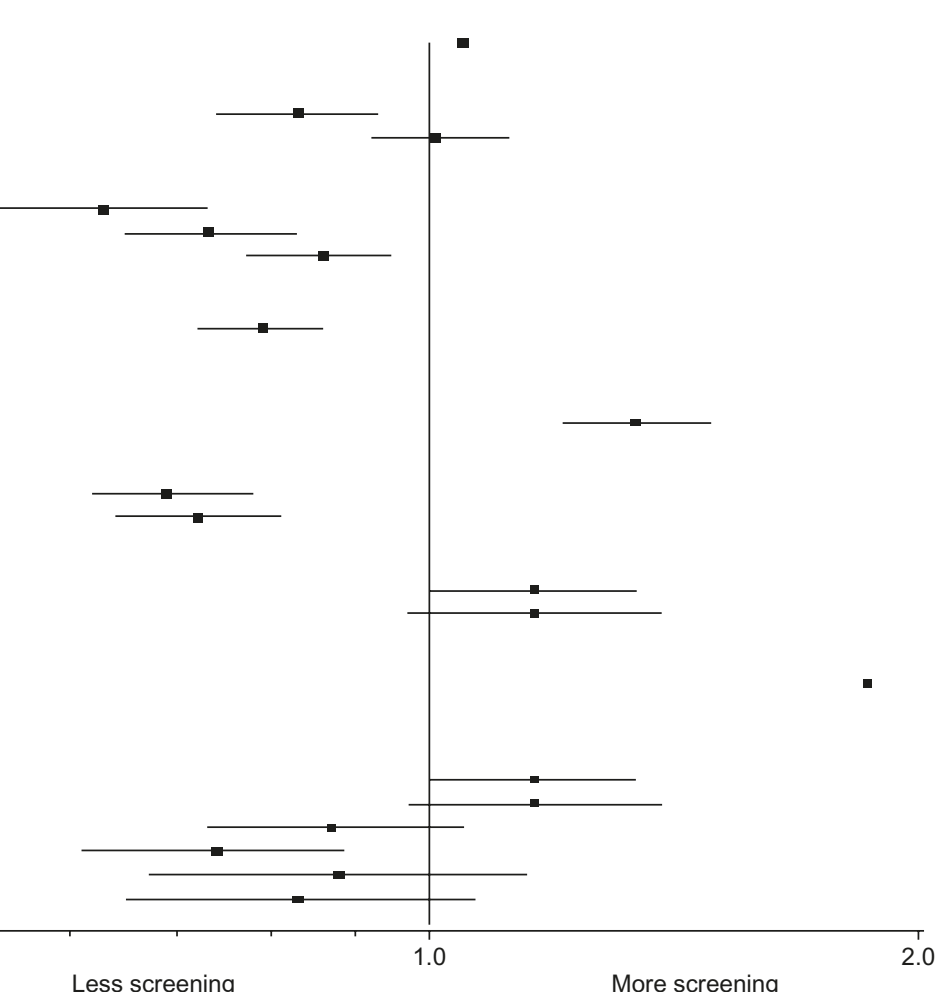

Figure I Adjusted odds ratios (OR) and $95 \%$ confidence intervals $(\mathrm{Cl})$ from multivariable logistic regression, where variables included in the model were age (as a continuous variable), education, household income, rurality, country of birth, marital status, level of disability, level of morbidity (ie, number of chronic conditions), and the interaction between level of disability and level of morbidity.

Notes: Data for $(\mathbf{A})$ women and $(\mathbf{B})$ men. “"*” denotes interaction term. 
are of lower socioeconomic status and have more chronic conditions than their peers, with women with disability being particularly affected.

Our findings suggest that an intermediate level of health care need (reflected in this study as level of disability and level of morbidity) may provide a benefit for cholesterol testing. In contrast, having health care needs that are either too few or too great seemingly has a negative effect on cholesterol testing. Although the reasons for these findings cannot be determined from these data, it is feasible that this is due to reduced health system contact for patients with few health care needs and too many competing demands at visits for patients with great health care needs. Our previous research showed that increasing health care needs led to less cervical cancer screening and, similar to what we have now found with cholesterol testing, that an intermediate level of health care need was associated with more breast cancer screening. ${ }^{9,10}$ An intermediate level of disability has previously been found to be associated with the highest level of receipt of immunization. ${ }^{21-23}$

Taken together, our body of work suggests that the chances of receiving appropriate preventative care in general are highest if a patient meets some minimum threshold for contact with their primary-care provider, if he or she does not have too many other competing health demands, and for those with other demands, if the preventative test requires minimal time on the part of the provider, such as giving a patient a laboratory requisition or completing a mammography referral. When seeing patients with high health care needs, primary-care physicians face many struggles, including difficulty simultaneously adhering to numerous guidelines, which are generally written for sole conditions, and insufficient consultation time. ${ }^{6,24-26}$ Future research should explore how physician reminder systems, patient recall systems, and non-physician health providers can surmount these barriers to providing quality preventive care for complex patients..$^{24,27-31}$ Reminder/recall systems could also be useful for patients with minimal health system contact. ${ }^{32,33}$

In line with other studies, including research from Ontario, we found that women were more likely to be up-todate on cholesterol testing than men. ${ }^{16,17,34,35}$ Men in Ontario have also previously been found to have a lower prevalence of being up-to-date on diabetes screening. ${ }^{36}$ As discussed earlier, these findings may reflect more regular contact with the health care system for women than men, which we also found with this study cohort. ${ }^{37}$ Interestingly, we also found that men who were in a married or common-law relationship (the majority of whom would be in a heterosexual relationship) were more likely to be up-to-date on testing than other men. The reasons for this are not known but possibilities include that women may be playing a role in encouraging testing for their male partners or that men with unhealthy behaviors are less likely to stay married. Men have previously been found to receive more health benefits from marriage than women, with married men showing lower levels of unhealthy behaviors such as alcohol consumption and cigarette smoking. ${ }^{38,39}$

This study has several limitations. First, we did not distinguish between the presence of chronic conditions that may increase the chance of cholesterol testing, such as heart disease or diabetes, and those that may distract from testing, such as COPD. Future research that makes this distinction is certainly warranted. However, this limitation does not discount our finding regarding people with no morbidity and no chronic conditions being underscreened. Second, many hospital laboratories in Ontario rely on a global budget and, therefore, do not bill the provincial health insurance plan for their services. Accordingly, we would have missed cholesterol tests that were performed within a hospital setting. The most complex patients may have been most likely to have their cholesterol testing ordered by a hospital-based specialist. Laboratories in rural areas may be more likely to be hospitalbased, which may partly explain our result of lower odds of testing for those living in rural versus urban areas; however, results from the regression models were adjusted for rurality. Third, disability and morbidity were measured at the beginning of each person's 3-year study period and may not have remained consistent over the entire study window. However, our 3-year time frame is still relatively short and it is unlikely that disability and morbidity category designation would change significantly in that time frame for a large number of patients. Fourth, the CCHS is voluntary and self-reported, and respondents may not be representative of the general population. However, it is designed by Statistics Canada to provide reliable population estimates. As well, self-reported morbidity has been found to have predictive validity of disability; measures of self-reported morbidity were strong predictors of disability as determined by medical assessment with tobit regression $t$-test values ranging from -2.73 to -5.11 in a study by Ferraro and $\mathrm{Su}^{40}$ Fifth, it is possible that if we had used a more liberal time frame (ie, 5 years instead of 3 years), then testing gaps would have been less. However, measures of disability and morbidity would have become less accurate and a 3-year period seemed to be the most appropriate based on not knowing participants' Framingham scores. Sixth, as our outcome is relatively common, the odds ratios described in this study cannot be interpreted as relative risks. Finally, we relied on administrative data that were not expressly collected for 
research purposes and were, therefore, unable to explore such issues as whether patients were offered testing but declined, or whether patients and providers underwent a process of shared decision-making around not testing. It is possible that patients may have had morbidity severe enough to make cholesterol testing inappropriate. However, using these administrative data allowed us to conduct a large, population-based study.

\section{Conclusion}

The prevalence of disability, and accordingly the coexistence of disability and multi-morbidity, will rise as our population continues to grow and age. ${ }^{41}$ Preventive care may be of particular importance for patients living with disability, but care is not being received equitably. Public health and practice-based interventions focused on reaching those with very low or high health care needs may need to be explored to further address these findings.

\section{Acknowledgments}

This research was supported by research grants from the Ontario Ministry of Health and Long Term Care (MOHLTC) to the Health System Performance Research Network. This study was also supported by the Institute for Clinical Evaluative Sciences (ICES), which is funded by an annual grant from the MOHLTC. The opinions, results and conclusions reported in this paper are those of the authors and are independent from the funding sources. No endorsement by ICES or the Ontario MOHLTC is intended or should be inferred. Parts of this material are based on data and information compiled and provided by CIHI. However, the analyses, conclusions, opinions and statements expressed herein are those of the author, and not necessarily those of CIHI. Dr Aisha Lofters is supported by a Canadian Cancer Society Research Institute Career Development Award in Cancer Prevention. Drs Lofters and Glazier are supported as Clinician Scientists in the Department of Family and Community Medicine at the University of Toronto and at St Michael's Hospital.

\section{Disclosure}

The authors report no conflict of interest in this work.

\section{References}

1. Saskatchewan Ministry of Advanced Education, Employment and Labour. Socio-Demographic Profiles of Saskatchewan Women: Women with Disabilities. Regina, SK: Saskatchewan Ministry of Advanced Education, Employment and Labour; 2009. Available from: http:// publications.gov.sk.ca/documents/17/39966-Socio-DemographicProfiles-Women-with-Disabilities.pdf. Accessed July 19, 2016.

2. Statistics Canada. A Profile of Disability in Canada, 2001. Ottawa, ON: Statistics Canada; 2003. Available from: http://www.statcan.gc.ca/ pub/89-577-x/index-eng.htm. Accessed July 19, 2016.
3. Lofters A, Guilcher S, Maulkhan N, Milligan J, Lee J. Patients living with disabilities: the need for quality primary care. Canadian Family Physician. In press 2015.

4. Guilcher SJ, Newman A, Jaglal SB. A comparison of cervical cancer screening rates among women with traumatic spinal cord injury and the general population. $J$ Womens Health (Larchmt). 2010;19(1):57-63.

5. Boult C, Counsell SR, Leipzig RM, Berenson RA. The urgency of preparing primary care physicians to care for older people with chronic illnesses. Health Aff (Millwood). 2010;29(5):811-818.

6. Sinnott C, Mc Hugh S, Browne J, Bradley C. GPs' perspectives on the management of patients with multimorbidity: systematic review and synthesis of qualitative research. BMJ Open. 2013;3(9):e003610.

7. Smeltzer SC. Preventive health screening for breast and cervical cancer and osteoporosis in women with physical disabilities. Fam Community Health. 2006;29(1 Suppl):35S-43S.

8. Kroll T, Jones GC, Kehn M, Neri MT. Barriers and strategies affecting the utilisation of primary preventive services for people with physical disabilities: a qualitative inquiry. Health Soc Care Community. 2006;14(4):284-293.

9. Lofters A, Guilcher S, Glazier RH, Jaglal S, Voth J, Bayoumi AM. Screening for cervical cancer in women with disability and multimorbidity: a retrospective cohort study in Ontario, Canada. CMAJ Open. 2014;2(4):E240-E247.

10. Guilcher SJ, Lofters A, Glazier RH, Jaglal SB, Voth J, Bayoumi AM. Level of disability, multi-morbidity and breast cancer screening: does severity matter? Prev Med. 2014;67:193-198.

11. Fortin M, Lapointe L, Hudon C, Vanasse A, Ntetu AL, Maltais D. Multimorbidity and quality of life in primary care: a systematic review. Health Qual Life Outcomes. 2004;2:51.

12. Payne RA, Abel GA, Guthrie B, Mercer SW. The effect of physical multimorbidity, mental health conditions and socioeconomic deprivation on unplanned admissions to hospital: a retrospective cohort study. CMAJ. 2013;185(5):E221-E228.

13. Lofters AK, Hwang SW, Moineddin R, Glazier RH. Cervical cancer screening among urban immigrants by region of origin: a populationbased cohort study. Prev Med. 2010;51(6):509-516.

14. Marshall JG, Cowell JM, Campbell ES, McNaughton DB. Regional variations in cancer screening rates found in women with diabetes. Nurs Res. 2010;59(1):34-41.

15. Anderson TJ, Gregoire J, Hegele RA, et al. 2012 update of the Canadian Cardiovascular Society guidelines for the diagnosis and treatment of dyslipidemia for the prevention of cardiovascular disease in the adult. Can J Cardiol. 2013;29(2):151-167.

16. Lugomirski P, Guo H, Boom NK, Donovan LR, Ko DT, Tu JV. Quality of diabetes and hyperlipidemia screening before a first myocardial infarction. Can J Cardiol. 2013;29(11):1382-1387.

17. OHIP Claims [database on the Internet]. ICES Data Toronto: Institute for Clinical Evaluative Sciences. Available from: http://www.ices.on.ca/ Data-and-Privacy/ICES-data. Accessed July 19, 2016.

18. Borkhoff CM, Saskin R, Rabeneck L, et al. Disparities in receipt of screening tests for cancer, diabetes and high cholesterol in Ontario, Canada: a population-based study using area-based methods. Can J Public Health. 2013;104(4):e284-e290.

19. Nasmith L, Kupka S, Ballem P, Creede C. Achieving care goals for people with chronic health conditions. Can Fam Physician. 2013;59(1):11-13, $15-17$.

20. Kralj B. Measuring "rurality" for purposes of health-care planning: an empirical measure for Ontario. Ont Med Rev. 2000;67(9):33-52.

21. Diab ME, Johnston MV. Relationships between level of disability and receipt of preventative health services. Arch Phys Med Rehabil. 2004;85(5):749-757.

22. Chan L, Doctor JN, MacLehose RF, et al. Do Medicare patients with disabilities receive preventive services? A population-based study. Arch Phys Med Rehabil. 1999;80(6):642-646.

23. Hoffman JM, Shumway-Cook A, Yorkston KM, Ciol MA, Dudgeon BJ, Chan L. Association of mobility limitations with health care satisfaction and use of preventive care: a survey of Medicare beneficiaries. Arch Phys Med Rehabil. 2007;88(5):583-588. 
24. Jaén CR, Stange KC, Nutting PA. Competing demands of primary care: a model for the delivery of clinical preventive services. J Fam Pract. 1994;38(2):166-171.

25. Steinman MA, Sudore RL, Peterson CA, Harlow JB, Fried TR. Influence of patient age and comorbid burden on clinician attitudes toward heart failure guidelines. Am J Geriatr Pharmacother. 2012;10(3): 211-218.

26. Solomon J, Raynor DK, Knapp P, Atkin K. The compatibility of prescribing guidelines and the doctor-patient partnership: a primary care mixed-methods study. Br J Gen Pract. 2012;62(597):e275-e281.

27. Sales A, Helfrich C, Ho PM, et al. Implementing electronic clinical reminders for lipid management in patients with ischemic heart disease in the veterans health administration: QUERI Series. Implement Sci. 2008;3:28

28. Kooy MJ, van Wijk BL, Heerdink ER, de Boer A, Bouvy ML. Does the use of an electronic reminder device with or without counseling improve adherence to lipid-lowering treatment? The results of a randomized controlled trial. Front Pharmacol. 2013;4:69.

29. Clark CE, Smith LF, Taylor RS, Campbell JL. Nurse-led interventions used to improve control of high blood pressure in people with diabetes: a systematic review and meta-analysis. Diabet Med. 2011;28(3): 250-261.

30. Ohman-Strickland PA, Orzano AJ, Hudson SV, et al. Quality of diabetes care in family medicine practices: influence of nurse-practitioners and physician's assistants. Ann Fam Med. 2008;6(1):14-22.

31. Health Quality Ontarios. Specialized nursing practice for chronic disease management in the primary care setting: an evidence-based analysis. Ont Health Technol Assess Ser. 2013;13(10):1-66.
32. Gurol-Urganci I, de Jongh T, Vodopivec-Jamsek V, Atun R, Car J. Mobile phone messaging reminders for attendance at healthcare appointments. Cochrane Database Syst Rev. 2013;12:CD007458.

33. Sequist TD, Zaslavsky AM, Marshall R, Fletcher RH, Ayanian JZ. Patient and physician reminders to promote colorectal cancer screening: a randomized controlled trial. Arch Intern Med. 2009;169(4):364-371.

34. Vaidya V, Partha G, Howe J. Utilization of preventive care services and their effect on cardiovascular outcomes in the United States. Risk Manag Healthc Policy. 2011;4:1-7.

35. Vaidya V, Partha G, Karmakar M. Gender differences in utilization of preventive care services in the United States. $J$ Womens Health (Larchmt). 2012;21(2):140-145.

36. Wilson SE, Rosella LC, Lipscombe LL, Manuel DG. The effectiveness and efficiency of diabetes screening in Ontario, Canada: a populationbased cohort study. BMC Public Health. 2010;10:506.

37. Bertakis KD, Azari R, Helms LJ, Callahan EJ, Robbins JA. Gender differences in the utilization of health care services. J Fam Pract. 2000;49(2):147-152.

38. Kalpakjian CZ, Houlihan B, Meade MA, et al. Marital status, marital transitions, well-being, and spinal cord injury: an examination of the effects of sex and time. Arch Phys Med Rehabil. 2011;92(3):433-440.

39. Lillard LA, Waite LJ. Til death do us part: marital disruption and mortality. Am JSociol. 1995;100(5):1131-1156.

40. Ferraro KF, Su YP. Physician-evaluated and self-reported morbidity for predicting disability. Am J Public Health. 2000;90(1):103-108.

41. Alwan A, Maclean DR, Riley LM, et al. Monitoring and surveillance of chronic non-communicable diseases: progress and capacity in highburden countries. Lancet. 2010;376(9755):1861-1868.
Clinical Epidemiology

\section{Publish your work in this journal}

Clinical Epidemiology is an international, peer-reviewed, open access, online journal focusing on disease and drug epidemiology, identification of risk factors and screening procedures to develop optimal preventative initiatives and programs. Specific topics include: diagnosis, prognosis, treatment, screening, prevention, risk factor modification,

Submit your manuscript here: https://www.dovepress.com/clinical-epidemiology-journal

\section{Dovepress}

systematic reviews, risk and safety of medical interventions, epidemiology and biostatistical methods, and evaluation of guidelines, translational medicine, health policies and economic evaluations. The manuscript management system is completely online and includes a very quick and fair peer-review system, which is all easy to use. 